\title{
Development and application of a chemical profiling method for the assessment of the quality and consistency of the Pelargonium sidoides extract
}

\author{
Se Mi Yu', Sung Jun Kim', Yeong Cheol Yoon ${ }^{2}$ and Jong Hoon Kim ${ }^{1 *}$ (1)
}

\begin{abstract}
The evaluation of chemical similarity is very significant for the evaluation and standardization of the quality of herbal medicines as the biological activity of herbal medicines depends on the composition and proportion of many individual components. Many health organizations have recommended chemical profiling for the quality and consistency evaluation of herbal medicines. In this study, chemical profiling was performed to evaluate the similarity between batches of Pelargonium sidoides maltodextrin mixture (PMM) from EPs ${ }^{\circledR} 7630$, a Pelargonium sidoides extract preparation. For chemical profile analysis, 7 common peaks were selected from 27 different PMM batches and specificity, linearity, accuracy, and precision tests were performed to develop the analytical method. The Pearson correlation coefficients of the similarity for all 27 batches manufactured over the years were higher than 0.90 , indicating that quality consistency is well ensured over the years. This profiling method confirms the chemical profile of various commercial products using not only PMM but also Pelargonium sidoides extract and shows that it can be applied to standardization of quality.
\end{abstract}

Keywords: Chemical profile, Quality consistency, Pelargonium sidoides, EPs ${ }^{\circledR}$ 7630, PMM, HPLC

\section{Introduction}

Herbal medicines have been utilized for centuries for the treatment of various diseases, based on their unique pharmacological and relatively minor side effects. Unlike synthetic drugs, whose active ingredients are clearly identified, the therapeutic effects of herbal medicines are derived from the synergistic effects of a multitude of components. Only in very rare cases are one or several components responsible for the overall biological efficacy of herbal medicines. Nevertheless, only a few markers or pharmacologically active components have been conventionally employed to assess the overall quality of herbal medicines. Therefore, a

\footnotetext{
*Correspondence: jonghoonk@hwpharm.com

${ }^{1}$ Research Center, Yang Ji Chemical, Suwon 16229, Republic of Korea Full list of author information is available at the end of the article
}

comprehensive approach such as fingerprint analysis has been suggested to control the quality of herbal medicines (Jin et al. 2006; Islam et al. 2012; Zhang et al. 2013; Goodarzi et al. 2013; Yin et al. 2015). Also, it is important to assess and evaluate chemical similarity of herbal medicines because their efficacy depends on the composition and proportions of various constituents (Tistaert et al. 2011). The concentrations of chemical components in herbal plants are affected by several factors, including geography, climate, age, harvesting season, soil type, and storage conditions. Even more variability is introduced by differences in the production processes of active ingredients. For these reasons, individual brands of herbal medicines from the same plant species may differ significantly in their biological activity and chemical composition. Therefore, quality control for chemical consistency is essential to ensure 
the efficacy of herbal medicines (Viapiana et al. 2016; $\mathrm{Lu}$ et al. 2018). Health organizations, including the US Food and Drug Administration (FDA), the World Health Organization (WHO), and the European Medicines Agency (EMA), have recommended this strategy for the evaluation of quality and similarity in herbal medicines (Xie et al. 2019; Zhu et al. 2020). Additionally, the Ministry of Food and Drug Safety (MFDS) of Korea has required chemical profiling of herbal medicines since October 2016 (Ministry of food and drug safety 2016).

Pelargonium sidoides, a medical plant indigenous to South Africa, is traditionally used for the treatment of various ailments and has been developed into an internationally successful herbal medicine to treat bronchitis and other respiratory-related ailments (Brendler and van Wyk 2008; Kumar et al. 2015). The original Pelargonium sidoides root extract, today known as EPs ${ }^{\circledR} 7630$, consists of many important secondary metabolites, including coumarins, phenolic acids, flavonoids, tannins, and their derivatives (Kolodziej 2020; Kolodziej 2007; Schotz and Noldner 2007; Schnitzler et al. 2008; Schoetz et al. 2008; Hauer et al. 2010; Maree and Viljoen 2012). The coumarins and their sulfate in an aqueous Pelargonium sidoides extract, EPs ${ }^{\circledR} 7630$, were characterized by LCMS (Schnitzler et al. 2008), and 15 benzopyranones and their sulfate esters of Pelargonium sidoides were identified by HPLC and NMR spectroscopy (Hauer et al. 2010). Other constituents of $\mathrm{EPs}^{\circledR} 7630$, which can easily be detected in the UV-chromatogram at $254 \mathrm{~nm}$, include purine derivatives. Along with guanosine $3^{\prime}, 5^{\prime}$-cyclic monophosphate (cGMP) and adenosine 3,5'-cyclic monophosphate (cAMP), a typical second messenger more often known from bacterial and mammalian cells, 1-methyl-cGMP, was identified (Wilson et al. 1978; Newton et al. 1984). Overall, both groups, coumarins and purine derivatives, account each for nearly $2 \%$ of dried EPs $^{\circledR} 7630$. They were also confirmed by LC-DAD-MS and NMR spectroscopy analysis (Schoetz et al. 2008).

Pelargonium sidoides maltodextrin mixture (PMM), which has also been used for chemical profiling, is a stabilized form of EPs ${ }^{\circledR} 7630$ (liquid extract of Pelargonium sidoides) with maltodextrin. It demonstrates the improved stability, is easier to handle, and can be used to prepare solid galenic dosage forms (Herrmann and Thole 2010). Therefore, PMM is considered advantageous for the analyses described herein.

Although several reports detailing the components of Pelargonium sidoides have been published, there is no standard profiling method described for the assessment of chemical similarity between individual batches. The aim of this study, therefore, was to develop and apply a profiling method for the evaluation of chemical similarities between different batches of Pelargonium sidoides extract, PMM, and other commercial products containing Pelargonium sidoides.

\section{Materials and methods \\ Plant material and reagents}

Batches of PMM (PMM-1-27) were provided by Dr. Willmar Schwabe, GmbH \& Co., KG (Germany). Umckalin, guanosine $3^{\prime}, 5^{\prime}$-cyclic monophosphate sodium salt (cGMP-Na), and adenosine 3,5'-cyclic monophosphate sodium salt (cAMP.Na) were purchased from each Santa Cruz Biotechnology (USA, 90\%), Sigma-Aldrich (USA, 100\%), and TCI (Japan, 98\%). All solvents used for LC analysis were of HPLC grade. Acetonitrile and methanol were obtained from J.T. Baker (USA). Trifluoroacetic acid (TFA, 90\%), formic acid (95\%), and acetic acid (99.85\%) were purchased from Sigma-Aldrich (USA). Deionized water was purified using a Cascada IX MK2 system (Pall, USA).

\section{Sample preparation}

PMM (100 mg) was dissolved in $10 \mathrm{ml}$ of $10 \%$ acetonitrile and ultrasonicated for 10 min (Powersonic 420, Hwashin tech Co., Ltd.). cGMP.Na and cAMP.Na were dissolved in water, respectively $(10 \mathrm{mg} / 10 \mathrm{ml})$. Umckalin was dissolved in acetonitrile $(5 \mathrm{mg} / 5 \mathrm{ml})$. All solutions were diluted with water. All samples were filtered with 0.45$\mu \mathrm{m}$ PVDF membrane filters (Pall, USA) and injected into the HPLC-PDA system.

\section{HPLC analysis}

HPLC of all samples was conducted on a Waters e2695 Alliance HPLC system (Waters Corp., Milford, MA, USA), equipped with a binary pump, an auto sampler, an online degasser, a column heater, a Waters 2998 Photodiode Array detector (PDA), and an Empower 3 data processing system. For the chromatographic analysis of various compounds of Pelargonium sidoides by HPLCPDA, all samples were separated in a Capcellpak AQ C18 column $(4.6 \times 250 \mathrm{~mm}$, particle size $5 \mu \mathrm{m}$; Osaka Soda, Japan) maintained at $40{ }^{\circ} \mathrm{C}$. The monitor was set at a wavelength of $254 \mathrm{~nm}$, and the injection volume was $20 \mu \mathrm{l}$. The mobile phases used were $0.02 \%(\mathrm{v} / \mathrm{v})$ trifluoroacetic acid in water $(\mathrm{A})$ and $0.2 \%(\mathrm{v} / \mathrm{v})$ trifluoroacetic acid in $50 \%$ acetonitrile (B), with a flow rate of $1 \mathrm{ml} / \mathrm{min}$. The gradient elution was set as follows: $0-10 \mathrm{~min}, 0 \%-5 \% \mathrm{~B}$; 10-65 $\mathrm{min}, 5 \%-50 \%$ B. Post-equilibration, the column was maintained at $0 \% \mathrm{~B}$ for $10 \mathrm{~min}$. The HPLC mobile phase was prepared fresh daily, filtered through a 0.45 $\mu \mathrm{m}$ membrane filter, and then degassed before injection. 


\section{LC-MS conditions}

Chromatographic separation was performed on an LC system using Acquity UPLC BEH C18 $(2.1 \times 150 \mathrm{~mm}$, $1.7 \mu \mathrm{m})$ and Capcellpak MG2 C18 $(3.0 \times 100 \mathrm{~mm}, 3 \mu \mathrm{m})$. The mobile phase for analysis of peak a-c consisted of (A) water with $0.1 \%(\mathrm{v} / \mathrm{v})$ formic acid and (B) acetonitrile with $0.1 \%(\mathrm{v} / \mathrm{v})$ formic acid. The gradient was as follows: $0-1 \mathrm{~min}, 5 \% \mathrm{~B}$; $1-9 \mathrm{~min}, 5 \%-80 \% \mathrm{~B}$; $9-12 \mathrm{~min}$, $80 \%-100 \% \mathrm{~B} ; 12-13 \mathrm{~min}, 100 \% \mathrm{~B}$. The flow rate was $0.4 \mathrm{ml} / \mathrm{min}$, and injection volume was $4 \mu \mathrm{l}$. HR-MS was performed using a LTQ-Orbitrap XL (Thermo Scientific, Waltham, Massachusetts, USA).

The mobile phase for analysis of peak $\mathrm{d}-\mathrm{g}$ consisted of (A) water with $0.02 \%(\mathrm{v} / \mathrm{v})$ trifluoroacetic acid and (B) $50 \%$ acetonitrile with $0.05 \%(\mathrm{v} / \mathrm{v})$ trifluoroacetic acid. The gradient was as follows; $0-7 \mathrm{~min}, 3 \% \mathrm{~B} ; 7-35 \mathrm{~min}$, $53 \%-50 \%$ B; $35-36$ min, $50 \%-100 \%$ B. The flow rate was $0.5 \mathrm{ml} / \mathrm{min}$, and injection volume was $20 \mu \mathrm{l}$. MS was performed using a LC-MS-8050 (Shimadzu, Japan).

The system was equipped with an ESI source that was operated in the positive ion mode with the following conditions: (HR-MS) spray voltage $3.5 \mathrm{kV}$, capillary voltage $20 \mathrm{~V}$, capillary temperature $350{ }^{\circ} \mathrm{C}$, mass scan range $\mathrm{m} / \mathrm{z}$ 100-1500, (ESI-MS) interface voltage $4.0 \mathrm{kV}$, interface temperature $300{ }^{\circ} \mathrm{C}$, DL temperature $250{ }^{\circ} \mathrm{C}$, mass scan range $m / z \quad 100-1500$. The Xcalibur software (Thermo Fisher Scientific) and Labsolution were used for data acquisition and processing. Peaks a-g were identified on the basis of comparison of retention times and MS spectral data with standard compounds or their reported literature data.

\section{Method validation}

The linearity was examined with standard solution and PMM solution. A mixed standard solution $(0.1 \mathrm{mg} / \mathrm{ml})$ of cAMP.Na, cGMP.Na and umckalin was prepared, along with calibration working standard solutions in water by appropriate dilution of the standard solution to yield five concentrations $(1,2,5,10,15 \mu \mathrm{g} / \mathrm{ml})$. And PMM solutions for calibration curve were prepared five concentrations $(50,80,100,120,200 \mathrm{mg} / 10 \mathrm{ml})$ in $10 \% \mathrm{ACN}$. The limits of detection (LOD) and quantification (LOQ) under the chromatographic conditions were calculated according to the following equations: $\mathrm{LOD}=3.3 \sigma / \mathrm{S}$ and $\mathrm{LOQ}=10 \sigma / \mathrm{S}$, where $\sigma$ and $S$ are the standard deviation of the response and the slope of the calibration curve. The accuracy test was carried out by recovery (\%) comparatively analyzing three levels $(80 \mathrm{mg} / 10 \mathrm{ml}, 100 \mathrm{mg} / 10 \mathrm{ml}, 120 \mathrm{mg} / 10 \mathrm{ml})$ of PMM in triplicates. Repeatability (intra-day) and intermediate precision (inter-day) for profiling method were performed according to the guideline on the Chemical Profile of Herbal Medicine (2016 edition) from MFDS of
Korea. Intra-day was validated by analyzing six independently prepared solution within 1 day. Inter-day precision was validated with the same sample over 3 days.

\section{Results and discussion Optimization of HPLC conditions}

To achieve the most chemical information and higher separation in the chromatographic profile of PMM, several factors including the compositions of the mobile phase, gradient elution, column types, temperatures, and detection wavelength were optimized at different respective conditions. Four types of analytical columns, including Capcellpack AQ $(5 \mu \mathrm{m}, 4.6 \times 250 \mathrm{~mm}$, Osaka Soda, Japan), Capcellpack UG120 ( $5 \mu \mathrm{m}, 4.6 \times 250 \mathrm{~mm}$, Osaka Soda, Japan), Luna $(5 \mu \mathrm{m}, 4.6 \times 250 \mathrm{~mm}$, Phenomenex, USA), and YMC pack ODS-AQ $(3 \mu \mathrm{m}, 4.6 \times 150 \mathrm{~mm}$, YMC, Japan) were evaluated. The Capcellpack AQ column was selected for analysis because it had the higher resolution and retention factor than other columns for all peaks. After selecting the column, column temperature test was performed at $30,35,40$, and $45^{\circ} \mathrm{C}$ using Capcellpack $A Q$ column. At all temperatures except for the $30^{\circ} \mathrm{C}$ symmetry factor, satisfactory resolution, symmetry factor and capacity factor were shown. This means it was robust at analysis temperature of $40^{\circ} \mathrm{C} \pm 5$ (Table 1). The mobile phase compositions of methanol-water and acetonitrilewater were compared, and acetonitrile-water was chosen as the most appropriate eluent. Since peak resolution was affected by the $\mathrm{pH}$ value in the mobile phase, several acids such as formic acid, acetic acid, and trifluoroacetic acid were added to the mobile phase to adjust the $\mathrm{pH}$. As a result, the addition of $0.02 \%(\mathrm{v} / \mathrm{v})$ and $0.2 \%(\mathrm{v} / \mathrm{v})$ trifluoroacetic acid into water and acetonitrile, respectively, was chosen to obtain a satisfactory resolution of the major peaks. Figure 1 shows the specific wavelengths of 7 peaks. Peaks a, b, c showed specific wavelengths at 256.6, 253.1, and $255.5 \mathrm{~nm}$, respectively. Peaks d, e, g showed specific wavelengths at $323.3,322.1$, and $326.8 \mathrm{~nm}$, and $\mathrm{f}$ at $297.0 \mathrm{~nm}$. Most of the seven peaks indicated their specific UV absorption values at around 254 or $330 \mathrm{~nm}$. Figure 2 shows the result of comparison among wavelengths of 210 to $330 \mathrm{~nm}$. Among these wavelengths, all peaks were detected only at 254 and $280 \mathrm{~nm}$, and in the case of $280 \mathrm{~nm}$, the peak $\mathrm{f}$ has a larger area value than the other peaks. The correlation coefficient can be greatly affected by the large area peaks. The wavelength of $254 \mathrm{~nm}$, which does not have a large difference in all peak areas, was considered the most appropriate. Also, the resolution values of peak $\mathrm{b}$ showed a slightly lower resolution of less than 1.5 at all UV wavelengths except $254 \mathrm{~nm}$ (Table 1). The optimal detection wavelength was set at $254 \mathrm{~nm}$ to develop a reliable fingerprint and for accurate analysis of the major peaks in PMM. 
Table 1 Comparison of column, column temperature and UV wavelength for optimization of analytical method

\begin{tabular}{|c|c|c|c|c|c|c|c|}
\hline Peak & a & b & c & d & e & $f$ & g \\
\hline \multicolumn{8}{|c|}{ Column } \\
\hline$C-1$ & ++ & ++ & ++ & ++ & ++ & ++ & ++ \\
\hline$C-2$ & ++ & ++ & ++ & ++ & ++ & ++ & ++ \\
\hline$C-3$ & + & - & + & + & ++ & ++ & ++ \\
\hline$C-4$ & - & - & ++ & - & ++ & ++ & ++ \\
\hline \multicolumn{8}{|c|}{ Column temp } \\
\hline $30^{\circ} \mathrm{C}$ & ++ & ++ & ++ & - & ++ & ++ & ++ \\
\hline $35^{\circ} \mathrm{C}$ & ++ & ++ & ++ & ++ & ++ & ++ & ++ \\
\hline $40^{\circ} \mathrm{C}$ & ++ & ++ & ++ & ++ & ++ & ++ & ++ \\
\hline $45^{\circ} \mathrm{C}$ & ++ & ++ & ++ & ++ & ++ & ++ & ++ \\
\hline \multicolumn{8}{|c|}{ UV wavelength } \\
\hline 210 & ++ & - & ++ & ++ & ++ & ++ & ++ \\
\hline 230 & ++ & - & ++ & ++ & ++ & ++ & ++ \\
\hline 254 & ++ & ++ & ++ & ++ & ++ & ++ & ++ \\
\hline 280 & ++ & + & ++ & ++ & ++ & ++ & ++ \\
\hline 300 & - & + & ++ & ++ & ++ & ++ & ++ \\
\hline 330 & - & - & - & ++ & ++ & ++ & ++ \\
\hline
\end{tabular}

C-1: Capcellpack AQ $(5 \mu \mathrm{m}, 4.6 \times 250 \mathrm{~mm}), \mathrm{C}-2$ : Capcellpack UG120 $(5 \mu \mathrm{m}, 4.6 \times 250 \mathrm{~mm}), \mathrm{C}-3$ : Luna $(5 \mu \mathrm{m}, 4.6 \times 250 \mathrm{~mm}), \mathrm{C}-4$ : YMC pack ODS-AQ $(3 \mu \mathrm{m}, 4.6 \times 150 \mathrm{~mm})$ Satisfaction of parameters: $(-)$ less than $2,(+)$ less than $3,(++)$ all satisfied. The results were evaluated based on the following parameters: resolution $(\geq 1.5)$, symmetry factor $(\leq 2.0)$ and capacity factor $(\geq 1.5)$

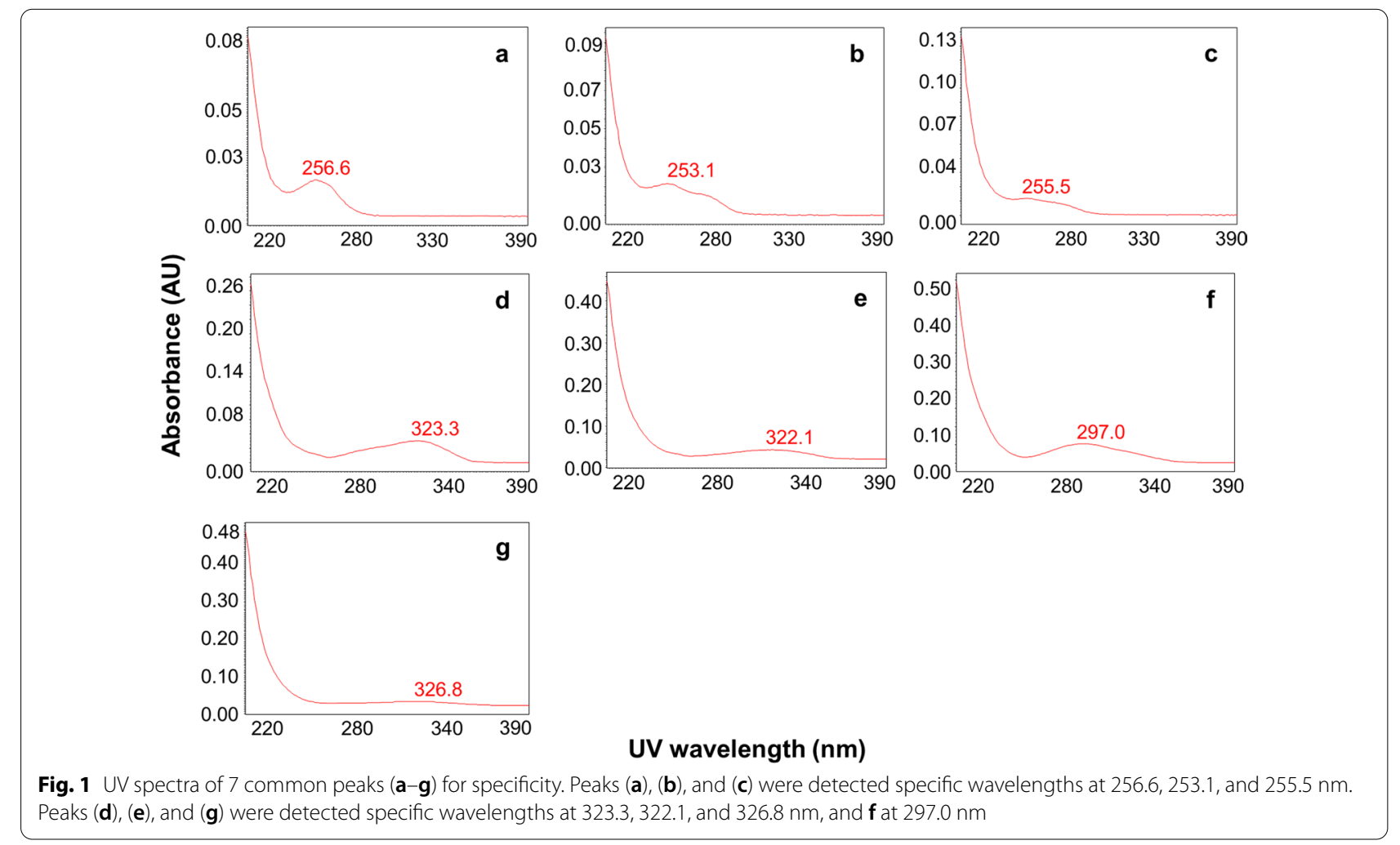




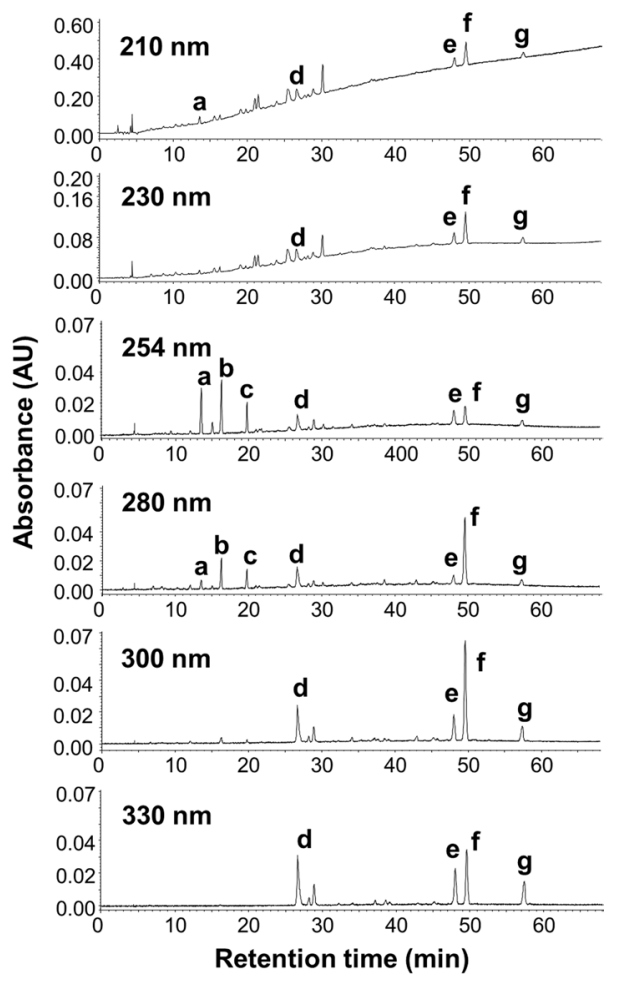

Fig. 2 Comparison of UV spectra (210-330 nm). All 7 common peaks $(a-c)$ were detected only 254 and $280 \mathrm{~nm}$ in our profile method. The figure showed that the wavelength of $254 \mathrm{~nm}$ does not have a large difference in all peak areas

Other factors, including flow rate, and the conditions of gradient elution were also individually tested at several levels. The optimal conditions for a given set of factors were considered based on the selectivity, resolution, and similar area values of all peaks. The optimal HPLC conditions used in this study are detailed in Section HPLC analysis.

\section{Validation of the analytical method}

The proposed method of HPLC profiling was validated in terms of specificity, linearity, accuracy, and precision (repeatability, intermediate precision). The specificity of the developed method was assessed using the retention time and pattern of the UV spectrum by comparing the chromatographic profile of the reference standards with that of PMM samples. The UV spectra of selected peaks were confirmed to be identical in the chromatograms of each batch. All the calibration curves showed good linear regression $\left(R^{2}>0.989\right)$ within test ranges. The values of LOD for ${ }_{\mathrm{C}} \mathrm{AMP},{ }_{\mathrm{C}} \mathrm{GMP}$, and Umckalin were 0.1629, 0.2507 and $0.2450 \mu \mathrm{g} / \mathrm{ml}$. LOQ was $0.4937,0.7597$, and $0.7425 \mu \mathrm{g} / \mathrm{ml}$, respectively, which indicated that the analytical method was acceptable with sufficient sensitivity. Linearity, LOD, LOQ, and accuracy test were performed with only the PMM solutions and three standard solutions. This is because standard other than ${ }_{C} \mathrm{AMP},{ }_{\mathrm{C}} \mathrm{GMP}$, and Umckalin is not commercially available. The repeatability (intra-day) and intermediate precision (inter-day) test were performed using one batch of PMM to express the mean, standard deviation, and relative standard deviation (RSD\%) values for retention time (RT) and peak area (PA). Additionally, relative retention time (RRT) and relative peak area (RPA) were calculated based on the first peak, which was the widest peak area. Repeatability was tested by running six independently prepared samples of identical concentration from one batch of PMM. The intermediate precision was carried out by the same method with the same batch but conducted by a different operator and on different days (1st, 3rd, and 5 th day). The RSD values of repeatability and intermediate precision for selected peaks were observed to be less than $5 \%$ for RT, RRT, PA, and RPA, respectively. The recovery values were $99.45-102.7 \%, 98.85-106.8 \%$, and $96.79-100.0 \%$ at 80,100 , and $120 \mathrm{mg} / 10 \mathrm{~mL}$ of PMM solution, respectively. All validation results of profile method are shown in Table 2.

\section{Identification of components of Pelargonium sidoides extract}

Among the seven major compounds identified in the chemical profile, three components (from peaks a, b, and g) were identified by comparing their UV spectrum and MS results with those of standard compounds. Peaks $\mathrm{c}-\mathrm{f}$ were identified by comparing the elution pattern of HPLC chromatogram and spectral results of MS and NMR with previously reported data (Schnitzler et al. 2008; Schoetz et al. 2008; Hauer et al. 2010). They were shown to be $330 \mathrm{~m} / z, 346 \mathrm{~m} / z, 355 \mathrm{~m} / z, 319 \mathrm{~m} / z$, $303 \mathrm{~m} / z$, and $223 \mathrm{~m} / z$ and their fragment ions (Table 3), which were identified as cAMP (peak a), cGMP (peak b), 1-methyl-cGMP (peak c), (peak d), 7-hydroxy-5,6dimethoxy-8-(sulfooxy)-2H-1-benzopyran-2-one (peak e), 5,6-dimethoxy-7-(sulfooxy)-2H-1-benzopyran-2-one (peak f), and 7-hydroxy-5,6-dimethoxy-2H-1-benzopyran-2-one (peak g) (Additional file 1). The seven components identified are shown in Fig. 3a-c being purine derivatives and $\mathrm{d}-\mathrm{g}$ being benzopyranone and sulfate ester. These components were used for the chemical profile of the PMM.

\section{Setting up the chemical profile}

The chemical profile for the evaluation of chemical consistency in PMM was obtained by optimizing the HPLC method to achieve a satisfactory resolution (Fig. 4). The chemical profile was generated based on the median of chromatograms in 10 different batches of PMM, in samples with similar HPLC profiles; in other words, the 
Table 2 Linearity, precision, and accuracy test for method validation

\begin{tabular}{|c|c|c|c|c|c|c|c|}
\hline Peak & a & b & c & d & e & $f$ & g \\
\hline \multicolumn{8}{|c|}{ Linearity, $L O D, L O Q$} \\
\hline $\mathrm{PMM}\left(\mathrm{R}^{2}\right)$ & 0.9994 & 0.9991 & 0.9975 & 0.9891 & 0.9981 & 0.9983 & 0.9952 \\
\hline Standard $\left(R^{2}\right)$ & 0.9999 & 0.9997 & - & - & - & - & 0.9996 \\
\hline $\operatorname{LOD}(\mu \mathrm{g} / \mathrm{ml})$ & 0.1629 & 0.2507 & - & - & - & - & 0.2450 \\
\hline LOQ $(\mu \mathrm{g} / \mathrm{ml})$ & 0.4937 & 0.7597 & - & - & - & - & 0.7425 \\
\hline \multicolumn{8}{|c|}{ Repeatability (intra-day), RSD (\%) } \\
\hline RT & 0.4304 & 0.3775 & 0.3304 & 0.1765 & 0.0727 & 0.0670 & 0.0714 \\
\hline RRT & 0.0000 & 0.0581 & 0.1445 & 0.2625 & 0.3578 & 0.3653 & 0.3787 \\
\hline PA & 1.427 & 1.404 & 3.027 & 3.681 & 2.663 & 3.277 & 2.646 \\
\hline RPA & 0.000 & 1.919 & 3.097 & 2.985 & 2.536 & 3.034 & 3.146 \\
\hline \multicolumn{8}{|c|}{ Intermediate precision (inter-day), RSD (\%) } \\
\hline RT & 0.2904 & 0.3194 & 0.2237 & 0.3616 & 0.1231 & 0.1259 & 0.0422 \\
\hline RRT & 0.0000 & 0.0454 & 0.0710 & 0.0736 & 0.1702 & 0.1710 & 0.2591 \\
\hline PA & 0.4555 & 1.324 & 4.972 & 3.151 & 3.169 & 2.308 & 0.2796 \\
\hline RPA & 0.0000 & 1.309 & 4.707 & 2.814 & 2.804 & 1.942 & 0.6872 \\
\hline \multicolumn{8}{|c|}{ Accuracy (recovery \%) } \\
\hline $80(\mathrm{mg} / 10 \mathrm{ml})$ & 100.3 & 99.45 & 102.2 & 99.21 & 102.3 & 100.6 & 102.7 \\
\hline $100(\mathrm{mg} / 10 \mathrm{ml})$ & 101.7 & 102.3 & 100.1 & 106.8 & 100.5 & 102.3 & 98.85 \\
\hline $120(\mathrm{mg} / 10 \mathrm{ml})$ & 100.0 & 99.77 & 96.84 & 96.79 & 98.50 & 99.23 & 98.57 \\
\hline
\end{tabular}

-: Standards are not commercially available

Table 3 MS fragmentation of 7 common peaks

\begin{tabular}{lll}
\hline Peak & Retention time & MS fragmentation $[\mathbf{M}+\mathbf{H}]^{+}\left(\mathbf{M S}^{\mathbf{2}}\right)$ \\
\hline a & 14.40 & $330(312,204,135)$ \\
b & 17.42 & $346(152,135)$ \\
c & 20.84 & $360(292,195,166,149)$ \\
d & 29.12 & $355(275,195)$ \\
e & 50.85 & $319(239)$ \\
f & 52.21 & $303(223)$ \\
g & 59.36 & $223(208)$ \\
\hline
\end{tabular}

average chromatogram from the samples was used as the standard chemical profile. Therefore, the evaluation of chemical similarities for PMM could be achieved using the standard chemical profile. Some peaks in all chromatograms that displayed reasonable heights and good resolution were assigned as "common peaks" to represent the characteristics of the Pelargonium sidoides extract (Viapiana et al. 2016; Yang et al. 2007; He et al. 2015). In the chemical profile studied in this work, seven common peaks were selected based on these criteria from the MFDS of Korea and were labeled by their elution order (peaks a-g). As shown in Fig. 4, these seven peaks were well separated under the given HPLC conditions. This indicates that optimal conditions were achieved for the comparative analysis of different batches of PMM.

\section{Establishment of a standard chemical profile}

The standard chemical profile as a criteria for similarity assessment was established in 10 batches of PMM (S-110) based on the developed method. As shown in Table 4, the RSD values of common peaks for each batch were below the guideline of $25 \%$.

\section{Evaluation of similarity between PMM samples}

It is necessary that the chemical profile of various constituents in PMM be evaluated for their similarities, which can be obtained from the calculation of the Pearson correlation coefficient according to the guideline on the Chemical Profile of Herbal Medicine (2016 edition) from the MFDS of Korea. A Pearson correlation coefficient value close to 1 indicates high similarity between samples. To compare the similarity between the overall chemical profiles of 27 batches of PMM and the standard chemical profile (i.e., the mean profiles of 10 batches of PMM), the correlation coefficients were calculated and are listed in Table 5. The Pearson correlation coefficient values of all 27 batches were shown to be greater than 0.90. Herein, PMM batches numbered with 1-5, $6-15,16-25$ and $26-27$ were manufactured in the year of 2017, 2018, 2019, and 2020, respectively. Despite being samples prepared in different years, the main chemical profile components detectable by HPLC appeared in a similar pattern (Fig. 5). This means that the quality of 


\section{a}<smiles>Nc1ncnc2c1ncn2[C@@H]1O[C@@H]2COP(=O)(O)O[C@H]2[C@H]1O</smiles>

d<smiles>O=c1ccc2cc(OS(=O)(=O)O)c(O)c(OS(=O)(=O)O)c2o1</smiles>

g<smiles>COc1c(O)cc2oc(=O)ccc2c1OC</smiles>

b<smiles>Nc1nc2c(ncn2[C@@H]2O[C@@H]3COP(=O)(O)O[C@H]3[C@H]2O)c(=O)[nH]1</smiles>

e<smiles>COc1c(O)c(OS(=O)(=O)O)c2oc(=O)ccc2c1OC</smiles><smiles>Cn1c(N)nc2c(ncn2[C@@H]2O[C@@H]3COP(=O)(O)O[C@@H]3[C@H]2O)c1=O</smiles>

f<smiles>COc1c(OS(=O)(=O)O)cc2oc(=O)ccc2c1OC</smiles>

Fig. 3 Chemical structure of 7 peaks for chemical profile. Adenosine 3',5'-cyclic monophosphate (a), Guanosine-3',5'-cyclomonophosphate (b), 1-Methyl guanosine-3',5'-cyclomonophosphate (c), 6,8-bis(sulfooxy)-7-hydroxy-2H-1-benzopyran-2- one (d), 7-hydroxy-5,6-dimethoxy-8-(s ulfooxy)-2H-1-benzopyran-2-one (e), 5,6-dimethoxy-7-(sulfooxy)-2H1-benzopyran-2-one (f), 7-hydroxy-5,6-dimethoxy2H-1-benzopyran-2-one (umckalin, g)

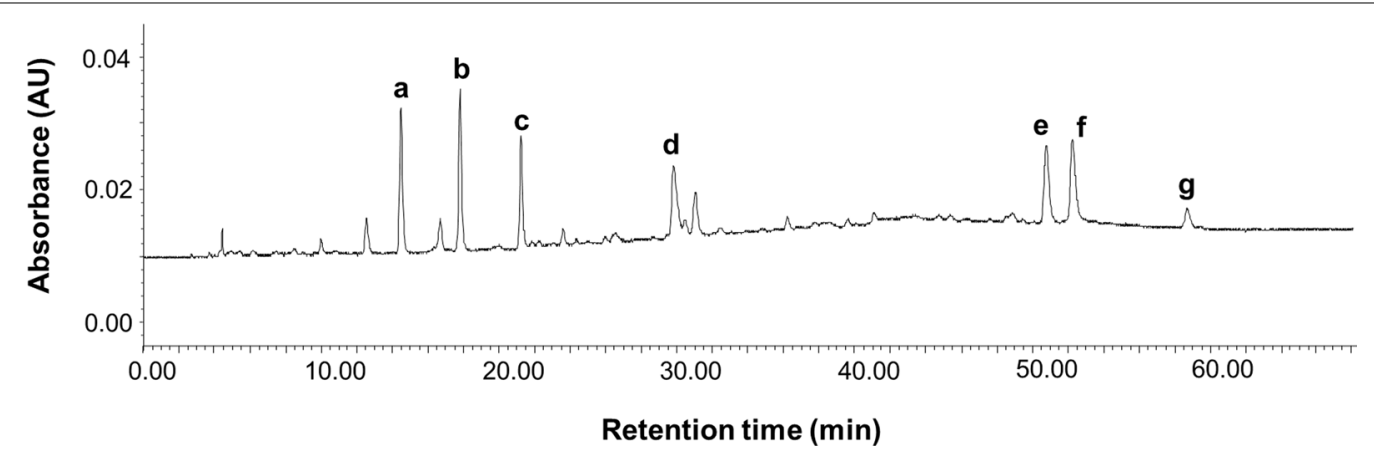

Fig. 4 HPLC chromatogram of PMM for chemical profile. Established chemical profile method: Capcellpak AQ C18 column (4.6 $250 \mathrm{~mm}, 5 \mu \mathrm{m})$ at $40^{\circ} \mathrm{C}$, wavelength $254 \mathrm{~nm}$, injection volume $20 \mu \mathrm{l}$. Mobile phase $0.02 \%(\mathrm{v} / \mathrm{v})$ trifluoroacetic acid in water (A) and $0.2 \%(\mathrm{v} / \mathrm{v})$ trifluoroacetic acid in $50 \%$ acetonitrile (B), flow rate $1 \mathrm{ml} / \mathrm{min}$. The gradient elution $0-10 \mathrm{~min}, 0 \%-5 \% \mathrm{~B} ; 10-65 \mathrm{~min}, 5 \%-50 \% \mathrm{~B}$

each batches manufactured by extracting Pelargonium sidoides over the years is well maintained.

Efficacy of herbal medicinal products has been acknowledged to be derived from various compounds in the products. Certain composition ratios of these compounds contribute to the overall efficacy of the products. The MFDS guideline on the chemical profile of herbal medicine proposes chemical profiles as a quality control method that can well reflect the composition and ratio of compounds (Ministry of food and drug safety 2016). Chemical profile provides comprehensive and consistent information on chemical properties of herbal medicinal products. Thus, the quality control by chemical profile could ensure the consistency, safety, and efficacy of herbal medicine. 
Table 4 Standard chemical profile for similarities assessment

\begin{tabular}{|c|c|c|c|c|c|c|c|}
\hline \multirow[t]{2}{*}{ Sample } & \multicolumn{7}{|c|}{ Peak (area) } \\
\hline & Peak a & Peak b & Peak c & Peak d & Peak e & Peak $f$ & Peak g \\
\hline$S-1$ & 194,093 & 179,992 & 87,875 & 159,542 & 147,473 & 148,462 & 68,325 \\
\hline$S-2$ & 191,457 & 183,094 & 86,748 & 150,425 & 140,105 & 135,229 & 69,569 \\
\hline S-3 & 248,738 & 247,343 & 117,324 & 209,413 & 167,066 & 195,996 & 79,346 \\
\hline S-4 & 213,404 & 222,153 & 107,794 & 201,631 & 162,009 & 190,874 & 90,770 \\
\hline S-5 & 205,491 & 222,664 & 101,749 & 206,892 & 161,417 & 180,162 & 84,216 \\
\hline S-6 & 211,865 & 221,438 & 159,656 & 210,268 & 175,786 & 190,963 & 88,471 \\
\hline S-7 & 219,847 & 229,170 & 162,491 & 226,487 & 185,504 & 191,227 & 95,272 \\
\hline S-8 & 435,125 & 391,586 & 251,664 & 218,733 & 252,867 & 249,194 & 97,202 \\
\hline S-9 & 402,466 & 379,953 & 233,052 & 182,507 & 241,683 & 251,533 & 127,437 \\
\hline$S-10$ & 336,114 & 318,179 & 261,993 & 219,258 & 234,165 & 301,463 & 88,358 \\
\hline Avg & 265,860 & 259,557 & 157,035 & 198,516 & 186,808 & 203,510 & 88,897 \\
\hline SD & 19,141 & 24,636 & 31,535 & 28,466 & 15,571 & 24,203 & 10,391 \\
\hline$\% R S D$ & 7.200 & 9.492 & 20.08 & 14.34 & 8.336 & 11.89 & 11.69 \\
\hline
\end{tabular}

S-1-10: PMM samples

Table 5 Equivalent correlation coefficient of PMM

\begin{tabular}{|c|c|c|c|c|c|c|c|c|c|}
\hline $\mathrm{Mfg}$ & Peak & Peak a (\%) & Peak b (\%) & Peak c (\%) & Peak d (\%) & Peak e (\%) & Peak f (\%) & Peak g (\%) & rvalue \\
\hline \multirow[t]{5}{*}{ (year)2017 } & PMM-1 & 8 & 26 & 13 & 10 & -16 & -5 & -31 & 0.96 \\
\hline & PMM-2 & 8 & 10 & -10 & 22 & -5 & 0 & -13 & 0.97 \\
\hline & PMM-3 & 3 & 7 & 6 & 19 & 1 & -11 & 17 & 0.96 \\
\hline & PMM-4 & -7 & -4 & 3 & 25 & -4 & -7 & -19 & 0.93 \\
\hline & PMM-5 & -10 & -5 & 1 & -2 & -14 & -20 & 40 & 0.93 \\
\hline \multirow[t]{10}{*}{2018} & PMM-6 & -24 & -25 & -39 & -8 & -10 & -23 & -47 & 0.94 \\
\hline & PMM-7 & -27 & -31 & -44 & -20 & -21 & -27 & -23 & 0.95 \\
\hline & PMM-8 & -28 & -29 & -45 & -24 & -25 & -34 & -22 & 0.96 \\
\hline & PMM-9 & -41 & -39 & -46 & -30 & -20 & -36 & -26 & 0.91 \\
\hline & PMM-10 & -38 & -37 & -44 & -24 & -21 & -36 & -19 & 0.92 \\
\hline & PMM-11 & 13 & 6 & 27 & -17 & -7 & -2 & 1 & 0.93 \\
\hline & PMM-12 & 31 & 30 & 55 & -9 & 5 & 17 & 0 & 0.91 \\
\hline & PMM-13 & -26 & -22 & -38 & -8 & -14 & -13 & -24 & 0.94 \\
\hline & PMM-14 & -6 & -5 & -25 & 5 & -11 & -4 & -11 & 0.97 \\
\hline & PMM-15 & -20 & -14 & -31 & 2 & -13 & -6 & 2 & 0.93 \\
\hline \multirow[t]{10}{*}{2019} & PMM-16 & -23 & -14 & -35 & 4 & -14 & -11 & -5 & 0.91 \\
\hline & PMM-17 & -20 & -15 & 2 & 6 & -6 & -6 & 0 & 0.94 \\
\hline & PMM-18 & -17 & -12 & 3 & 14 & -1 & -6 & 7 & 0.92 \\
\hline & PMM-19 & -3 & 6 & 21 & 1 & 21 & 16 & -33 & 0.94 \\
\hline & PMM-20 & -4 & 3 & 19 & 4 & 20 & 19 & -34 & 0.93 \\
\hline & PMM-21 & 64 & 51 & 60 & 10 & 35 & 22 & 9 & 0.94 \\
\hline & PMM-22 & 58 & 56 & 52 & -1 & 39 & 21 & 51 & 0.90 \\
\hline & PMM-23 & 51 & 46 & 48 & -8 & 29 & 24 & 43 & 0.90 \\
\hline & PMM-24 & 59 & 55 & 59 & 0 & 43 & 26 & 44 & 0.91 \\
\hline & PMM-25 & 69 & 54 & 58 & 7 & 41 & 27 & 15 & 0.94 \\
\hline \multirow[t]{2}{*}{2020} & PMM-26 & 26 & 23 & 67 & 10 & 25 & 48 & -1 & 0.91 \\
\hline & PMM-27 & 4 & 1 & 31 & -9 & 4 & 20 & 6 & 0.93 \\
\hline
\end{tabular}

$r$ value: Pearson correlation coefficient

(\%): Ratio of increase or decrease compared to standard chemical profile indicated in Table 4 


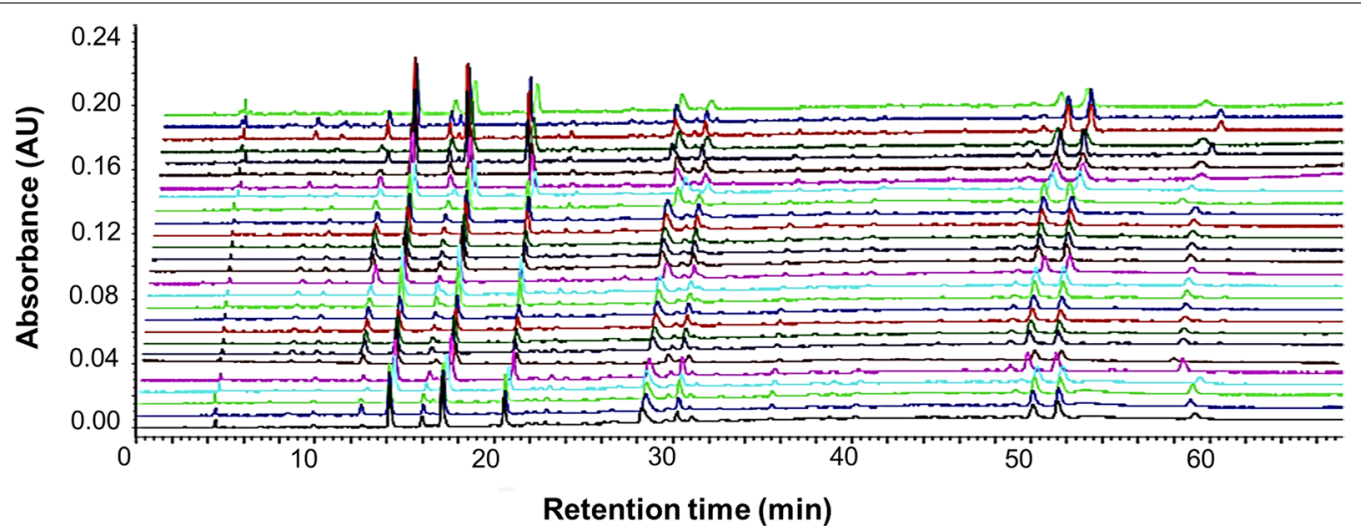

Fig. 5 Total chromatograms of 27 PMM batches with similar patterns between different batches

\section{Conclusion}

In this study, a chemical profiling method for evaluating quality consistency of PMM from EPs ${ }^{\circledR} 7630$ was developed. The specificity, linearity, accuracy, and precision (repeatability, intermediate precision) of the developed chemical profiling method were validated. The results of the validation indicated that the developed method was practical and reliable, with high sensitivity and efficiency. Seven common peaks were selected to comprise of the chemical profile. The chemical profile of all PMM batches manufactured in different years using these common peaks had Pearson correlation coefficient (r) values higher than 0.90 . The profiling method is suitable for the evaluation of the quality and similarity of PMM between batches. The chemical profile developed herein by seven common peaks can be applied as a criteria for improved quality control of any products using Pelargonium sidoides extracts.

\section{Abbreviations}

PMM: Pelargonium sidoides maltodextrin mixture; FDA: Food and Drug Administration; WHO: World Health Organization; EMA: European Medicines Agency; MFDS: Ministry of Food and Drug Safety; cGMP: Guanosine 3',5'-cyclic monophosphate; cAMP: Adenosine 3',5'-cyclic monophosphate; LOD: Limits of detection; LOQ: Limits of quantification; RT: Retention time; PA: Peak area; RRT: Relative retention time; RPA: Relative peak area.

\section{Supplementary Information}

The online version contains supplementary material available at https://doi. org/10.1186/s40543-021-00297-z.

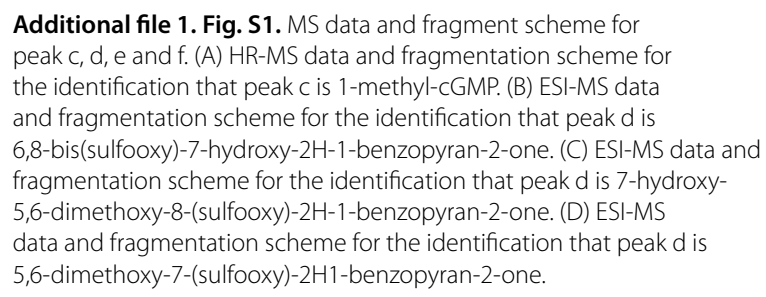

\section{Acknowledgements}

Not applicable.

\section{Authors' contributions}

All authors read and approved the final version of the manuscript for publication.

\section{Funding}

Not applicable.

\section{Availability of data and materials}

All data generated or analyzed during this study are included in this published article (and its Additional file 1 file).

\section{Declarations}

\section{Competing interests}

The authors declare that they have no competing interests.

\section{Author details}

${ }^{1}$ Research Center, Yang Ji Chemical, Suwon 16229, Republic of Korea.

${ }^{2}$ Research and Development Center, Han Wha Pharma. Co., Ltd,

Chuncheon 24468, Republic of Korea.

Received: 12 April 2021 Accepted: 1 October 2021

Published online: 13 October 2021

\section{References}

Brendler T, van Wyk BE. A historical, scientific and commercial perspective on the medicinal use of Pelargonium sidoides (Geraniaceae). J Ethnopharmacol. 2008;119:420-33. https://doi.org/10.1016/j.jep.2008.07.037.

Goodarzi M, Russell PJ, Vander HY. Similarity analyses of chromatographic herbal fingerprints: a review. Anal Chim Acta. 2013;804:16-28. https://doi. org/10.1016/j.aca.2013.09.017.

Hauer H, Germer S, Elsasser J, Ritter T. Benzopyranones and their sulfate esters from Pelargonium sidoides. Planta Med. 2010;76:350-2. https://doi.org/10. 1055/s-2007-986775.

He X, Li J, Zhao W, Liu R, Zhang L, Kong X. Chemical fingerprint analysis for quality control and identification of Ziyang green tea by HPLC. Food Chem. 2015;171:405-11. https://doi.org/10.1016/j.foodchem.2014.09.026.

Herrmann J, Thole M. Dry extracts of pelargonium sidoides and pelargonium reniforme. US20100112096A1. 2010. https://patents.google.com/patent/ US20100112096A1/en.

Islam MN, Kim U, Kim DH, Dong MS, Yoo HH. High-performance liquid chromatography-based multivariate analysis to predict the estrogenic activity of an Epimedium koreanum extract. Biosci Biotechnol Biochem. 2012;76:923-7. https://doi.org/10.1271/bbb.110922. 
Jin W, Ge RL, Wei QJ, Bao TY, Shi HM, Tu PF. Development of high-performance liquid chromatographic fingerprint for the quality control of Rheum tanguticum Maxim. ex Balf. J Chromatogr A. 2006;1132:320-4. https://doi. org/10.1016/j.chroma.2006.08.022

Kolodziej H. Fascinating metabolic pools of Pelargonium sidoides and Pelargonium reniforme, traditional and phytomedicinal sources of the herbal medicine Umckaloabo. Phytomedicine. 2007;14(Suppl 6):9-17. https:// doi.org/10.1016/j.phymed.2006.11.021.

Kolodziej H. Traditionally used Pelargonium species: chemistry and biological activity of umckaloabo extracts and their constituents. Current Topic in Phytochemical. 2020;3:77-93.

Kumar V, Moyo M, Gruz J, Šubrtová M, Van Staden J. Phenolic acid profiles and antioxidant potential of Pelargonium sidoides callus cultures. Ind Crops Prod. 2015;77:402-8. https://doi.org/10.1016/j.indcrop.2015.09.009.

Lu H, Ju M, Chu S, Xu T, Huang Y, Chan Q, Peng H, Gui S. Quantitative and chemical fingerprint analysis for the quality evaluation of platycodi radix collected from various regions in China by HPLC coupled with chemometrics. Molecules. 2018;23:1823. https://doi.org/10.3390/molec ules23071823.

Maree JE, Viljoen AM. Phytochemical distinction between Pelargonium sidoides and Pelargonium reniforme - a quality control perspective. S Afr J Bot. 2012;82:83-91. https://doi.org/10.1016/j.sajb.2012.07.007.

Ministry of Food and Drug Safety. Guideline on establishment of chemical profiles for herbal medicinal products (English version). 2016. https:// www.nifds.go.kr/brd/m_15/view.do?seq $=12718 \& \mathrm{srchFr}=\& \mathrm{srchTo}=\&$ srchWord=\&srchTp=\&itm_seq_1=0\&itm_seq_2=0\&multi_itm_seq=0\& company_cd=\&company_nm $=$ \&page $=1$.

Newton RP, Kingston EE, Evans DE, Younis LM, Brown EG. Occurrence of guanosine 3',5'-cyclic monophosphate (Cyclic GMP) and associated enzyme systems in Phaseolus vulgaris. Phytochemistry. 1984;23:1367-72. https://doi.org/10.1016/S0031-9422(00)80467-7.

Schnitzler P, Schneider S, Stintzing FC, Carle R, Reichling J. Efficacy of an aqueous Pelargonium sidoides extract against herpesvirus. Phytomedicine. 2008;15:1108-16. https://doi.org/10.1016/j.phymed.2008.06.009.

Schoetz K, Erdelmeier C, Germer S, Hauer H. A detailed view on the constituents of EPs ${ }^{\circledR}$ 7630. Planta Med. 2008;74:667-74. https://doi.org/10.1055/s2008-1074515.
Schotz K, Noldner M. Mass spectroscopic characterisation of oligomeric proanthocyanidins derived from an extract of Pelargonium sidoides roots (EPs ${ }^{\circledR}$ 7630) and pharmacological screening in CNS models. Phytomedicine. 2007;14(Suppl 6):32-9. https://doi.org/10.1016/j.phymed.2006.11.019.

Tistaert C, Dejaegher B, Vander HY. Chromatographic separation techniques and data handling methods for herbal fingerprints: a review. Anal Chim Acta. 2011;690:148-61. https://doi.org/10.1016/j.aca.2011.02.023.

Viapiana A, Struck-Lewicka W, Konieczynski P, Wesolowski M, Kaliszan R. An approach based on HPLC-fingerprint and chemometrics to quality consistency evaluation of Matricaria chamomilla L. commercial samples. Front Plant Sci. 2016;7:1561. https://doi.org/10.3389/fpls.2016.01561.

Wilson T, Moustafa E, Renwick AG. Isolation, characterization and distribution of adenosine 3': 5'-cyclic monophosphate from Pinus radiata. Biocheml J. 1978;175:931-6. https://doi.org/10.1042/bj1750931.

Xie G, Xu Q, Li R, Shi L, Han Y, Zhu Y, Wu G, Qin M. Chemical profiles and quality evaluation of Buddleja officinalis flowers by HPLC-DAD and HPLC-Q-TOFMS/MS. J Pharm Biomed Anal. 2019;164:283-95. https://doi.org/10.1016/j. jpba.2018.10.030

Yang D, Liang Z, Duan Q, Zhang Y. Quality assessment of cardiotonic pills by HPLC fingerprinting. Chroma. 2007;66:509-14. https://doi.org/10.1365/ s10337-007-0359-7.

Yin FZ, Li L, LuTL, Li WD, Cai BC, Yin W. Quality assessment of Psoralea fructus by HPLC fingerprint coupled with multi-components analysis. Indian J Pharm Sci. 2015;77:715-22. https://doi.org/10.4103/0250-474x.174996.

Zhang QF, Cheung HY, Zeng LB. Development of HPLC fingerprint for species differentiation and quality assessment of Rhizoma Smilacis Glabrae. J Nat Med. 2013;67:207-11. https://doi.org/10.1007/s11418-012-0648-9.

Zhu Y, Du P, Huang S, Yin Q, Yang Y. Quality assessment of Moringa seed shells based on fingerprinting using HPLC-DAD. Acta Chromatogr. 2020;32:2833. https://doi.org/10.1556/1326.2019.00545.

\section{Publisher's Note}

Springer Nature remains neutral with regard to jurisdictional claims in published maps and institutional affiliations.

\section{Submit your manuscript to a SpringerOpen ${ }^{\circ}$ journal and benefit from:}

- Convenient online submission

- Rigorous peer review

- Open access: articles freely available online

- High visibility within the field

- Retaining the copyright to your article

Submit your next manuscript at $\boldsymbol{\nabla}$ springeropen.com 